\title{
ASSESSMENT TECHNIQUES FOR MEASURING TENSILE ADHESIVE FORCES OF WET AND STICKY ORES*
}

Kenneth Williams ${ }^{1}$ Jens Plinke ${ }^{2}$ Wei Chen ${ }^{3}$

\begin{abstract}
Economic drives dictate the exploitation of formerly less attractive ore bodies located close to or even beneath the water table. These ores can cause handling problems and expensive downtime of processing equipment due to their increased adhesive characteristics and are colloquially termed as "wet and sticky" ores. In order to gain a better understanding of the causes of poor handleability, experimental test methods for wall and inter-particle adhesion within bulk solids samples were developed and validated. The results confirmed that adhesion of bulk solid to equipment surfaces is mainly governed by capillary pressure. It can therefore be described using the Young-Laplace equation, which implies that adhesion is primarily dependent on the interfacial water between bulk material and the adhesion partner. Accordingly, the governing material parameters of adhesion are its capillarity and permeability, as these two characterize water transport to or from the interface of the adhesion partners. Furthermore a threshold for the classification of a material as wet and sticky based on the measurements of adhesion has been proposed.
\end{abstract}

Keywords: Bulk solids; Adhesion; Wets and sticky ores; Materials handling.

1 PhD, TUNRA Bulk Solids - Research, Newcastle Institute for Energy and Resources, University of Newcastle, Callaghan, NSW, Australia.

2 PhD candidate, TUNRA Bulk Solids - Research, Newcastle Institute for Energy and Resources, University of Newcastle, Callaghan, NSW, Australia.

3 PhD, TUNRA Bulk Solids - Research, Newcastle Institute for Energy and Resources, University of Newcastle, Callaghan, NSW, Australia. 


\section{INTRODUCTION}

Macroscopic adhesion only occurs when a material is adhesive enough to adhere to equipment surfaces (wall adhesion) as well as adhesive or cohesive enough to adhere to the first layers of material adhering to the equipment surfaces [1]. It is therefore necessary to consider both mechanisms when investigating issues of clogging and build-up.

Burbaum [1] and Habenicht [2] proposed and validated the model illustrated in Figure 1 for the capillary pressure force $\left(F_{c}\right)$ between two steel surfaces connected by a liquid film based on the Young-Laplace equation. Burbaum applied it to a similar adhesion test between clay samples and stainless steel surfaces.

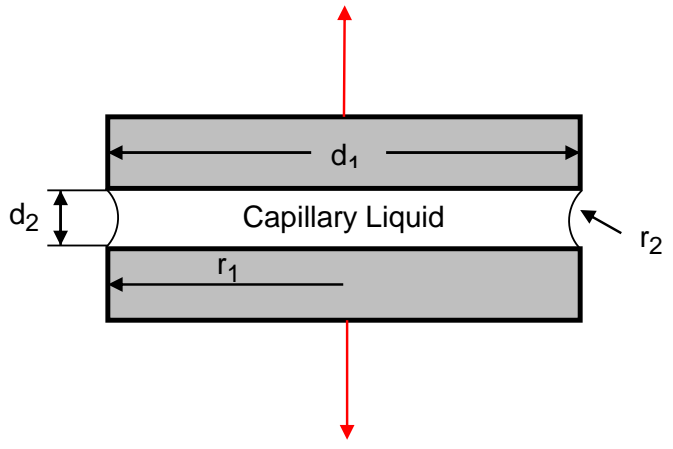

$$
F_{C}=\gamma *\left(\frac{1}{r_{1}}+\frac{2}{d_{2}}\right) * \pi r_{1}^{2}
$$

Figure 1: Capillary model based on simplified Young-Laplace equation

\section{TEST EQUIPMENT}

The TBS wall adhesion test measures the tensile force required to pull off a bulk solid sample from a material surface in the vertical direction. The TBS inter-particle adhesion test allows the measurement of the force required to fracture a sample consolidated into in a cylindrical split cell. The schematic designs are shown in Figure 2. The consolidation process follows the standard wall friction testing technique, as described in [3].

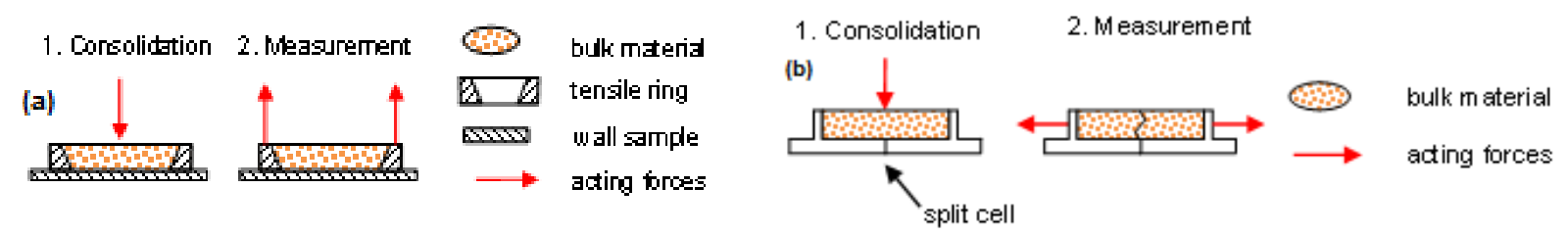

Figure 2: Schematic design of (a) TBS wall adhesion test and (b) TBS inter-particle adhesion

Table 1: Repeatability of the tests

\begin{tabular}{|l|c|c|c|c|c|}
\hline Test & $\begin{array}{c}\text { No. of } \\
\text { tests }\end{array}$ & $\begin{array}{c}\text { Mean value } \\
{[\mathrm{Pa}]}\end{array}$ & $\begin{array}{c}\text { Variance } \\
{\left[\mathrm{Pa}^{2}\right]}\end{array}$ & $\begin{array}{c}\text { STD } \\
{[\mathrm{Pa}]}\end{array}$ & $\begin{array}{c}\text { CV } \\
{[\%]}\end{array}$ \\
\hline $\begin{array}{l}\text { Wall adhesion tensile } \\
\text { test }\end{array}$ & 7 & 1082.9 & 11283.4 & 106.55 & 9.8 \\
\hline $\begin{array}{l}\text { Inter-particle adhesion } \\
\text { tensile test }\end{array}$ & 15 & 590.07 & 27306.8 & 165.2 & 28.0 \\
\hline
\end{tabular}




\section{INVESTIGATIONS AND CHARACTERIZATION OF WET AND STICKY ORES (WSO)}

The adhesive characteristics of two ores, generally characterized as WSO during mining operations were investigated. A minimum of three repetitions have been for each test. The two adhesion test method results are discussed below.

\subsection{Wall adhesive tensile tests}

Wall adhesion tests were conducted on a Stainless Steel (STS) sample with a 2B finish and an Arcoplate (ARC) sample. These two samples represent opposite ends of the spectrum of wall materials likely to be encountered in bulk solids handling, with roughness of $R a=0.8$ (Stainless Steel) and $R a=19.3$ (Arcoplate).

The adhesive tensile stress of the ore 1 is highly dependent on the moisture content (Figure 3a). The wall material does not have any significant influence on the adhesion force. Figure $3 \mathrm{~b}$ shows the adhesive tensile stress measured for the ore 2, paired with the Stainless Steel wall sample. Figure $3 \mathrm{c}$ is the equivalent measurement using Arcoplate as the adhesion partner. From $12 \%$ to $15 \%$ MC the adhesive tensile stress increases, whereas at higher $\mathrm{MC}$ it decreases again. The wall sample does not show any influence on the adhesive tensile stress. This supports the theory that the adhesion is a result of capillary effects.
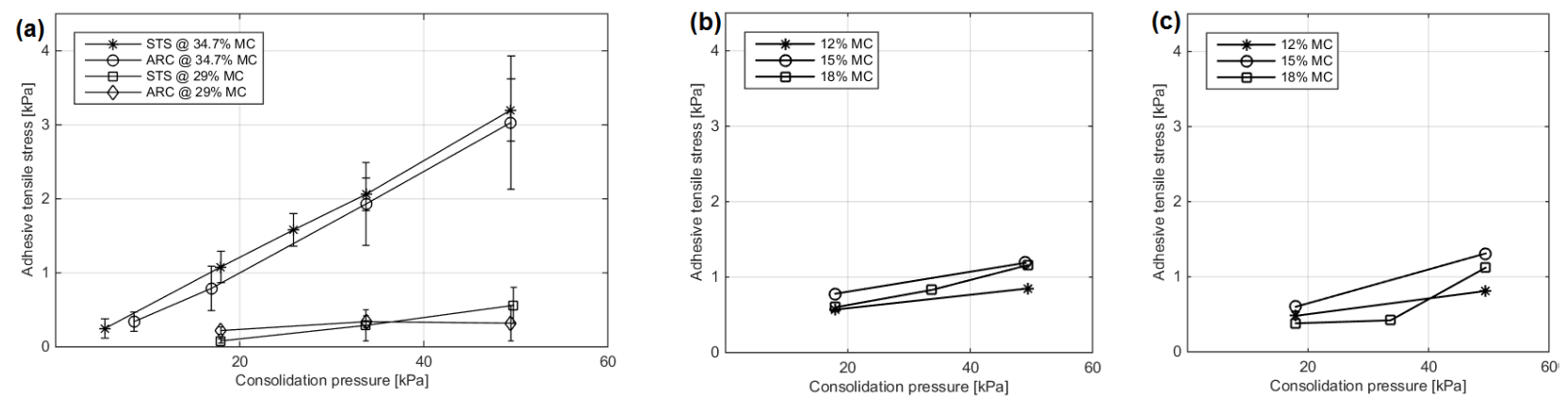

Figure 3: Adhesive tensile stress of (a) ore 1, (b) adhesive tensile stress of ore 2 on Stainless Steel wall sample and (c) Arcoplate.

\subsection{Inter-particle adhesive tensile tests}

The ore 1 was tested at three different moisture contents regarding the inter-particle adhesive tensile strength, as shown in Figure 4a. The stress necessary for failure increases with increasing moisture content of the sample as well as with increasing consolidation load. Figure $4 \mathrm{~b}$ shows a plot of the tensile measurements of the ore 2 . The measurements conducted show a large influence of the moisture content. 

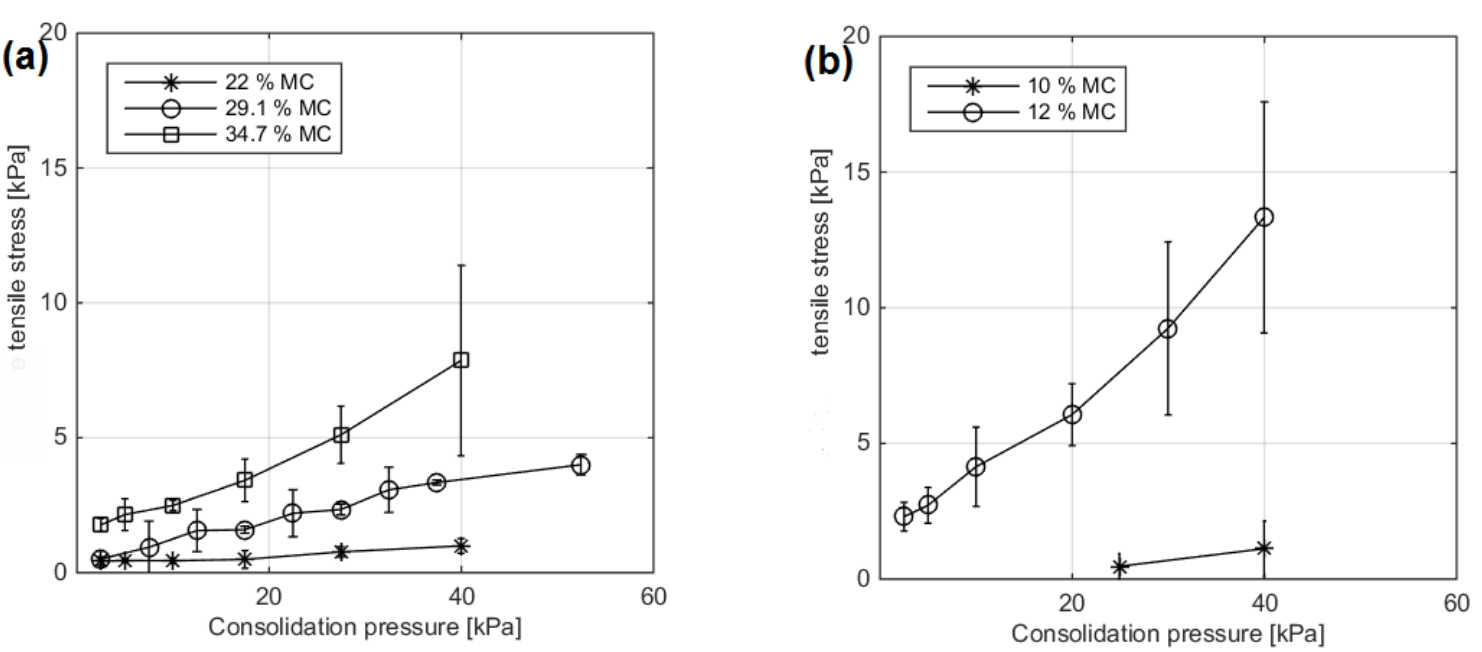

Figure 4: Cohesive tensile stress of (a), the ore 1 and (b) ore 2

\section{WSO CLASSIFICATION}

It is beneficial to classify materials as wet and sticky based on the weaker of the two mechanisms described above, since the weaker mechanism will determine failure of build-up on the wall. The minimum adhesion threshold is set at $500 \mathrm{~Pa}$. This adhesion value ensures for the common bulk density of $\sim 2000 \mathrm{~kg} / \mathrm{m}^{3}$ that the adhesion stress is sufficient to support an adhesion layer of $2.5 \mathrm{~cm}$ thickness. Since the materials tested are known for handling problems in industrial applications, they exceed the proposed adhesive threshold at any given moisture content for at least one of the wall samples.

Figure $5 \mathrm{a}$ summarizes the information gathered for the classification of ore 1 at $21.9 \% \mathrm{MC}$. Figure $5 \mathrm{~b}$ shows the corresponding information at the $34.7 \% \mathrm{MC}$. At this moisture content the ore can be considered as a problematic wet and sticky ore. The ore 2 is classified in a similar manner.

Table 2: classification of tested materials

\begin{tabular}{|l|l|l|l|l|}
\hline \multirow{2}{*}{ Material } & $\begin{array}{l}\text { Moisture content } \\
{[\%]}\end{array}$ & $\begin{array}{l}\text { Wall Adhesion } \\
\text { Value }\end{array}$ & $\begin{array}{l}\text { Inter-particle } \\
\text { Value }\end{array}$ & Classification \\
\hline \multirow{2}{*}{ Ore 1} & 29.1 & ET & BT & NWSM \\
\cline { 2 - 5 } & 34.7 & ET & ET & WSM \\
\hline \multirow{4}{*}{ Ore 2} & 10 & ET & BT & NWSM \\
\cline { 2 - 5 } & 12 & ET & ET & WSM \\
\cline { 2 - 5 } & 15 & ET & ET & WSM \\
\cline { 2 - 5 } & 18 & ET & WSM \\
\hline \multirow{2}{*}{$\begin{array}{l}\text { ET - exceeds threshold; BT - below threshold; WSM - wet and sticky material; NWSM - non } \\
\text { wet and sticky material }\end{array}$} & \multicolumn{4}{l}{} \\
\hline
\end{tabular}



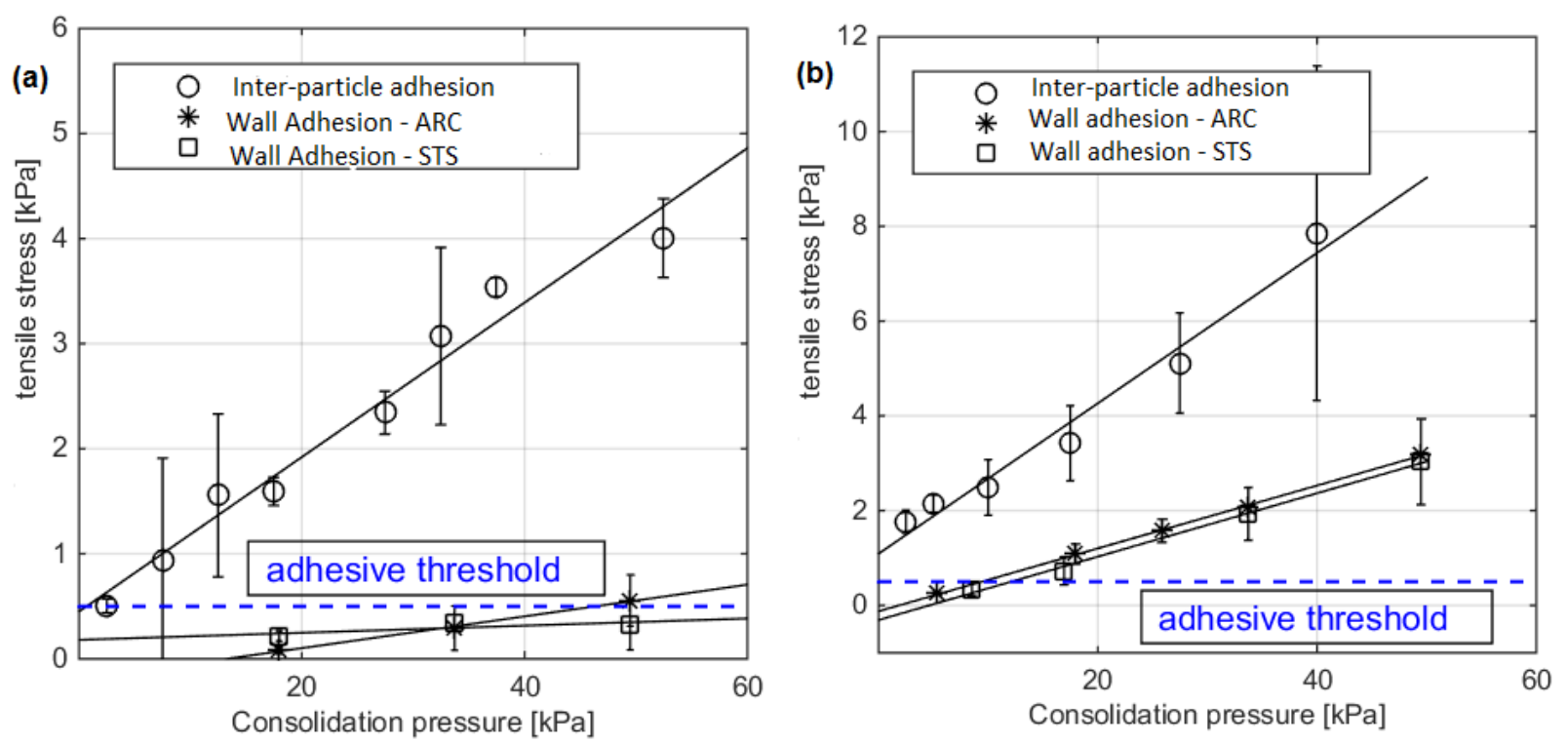

Figure 5: Classification of (a) ore 1 at $29.1 \%$ moisture and (b) $34.7 \%$ moisture

\section{CONCLUSION}

The wall adhesive tensile stress was found to be mainly dependent on capillary forces and can therefore be described using the Young-Laplace equation. The capillary forces are governed by the thickness of the liquid film in the contact interface. Therefore the adhesive tensile stress is independent on the wall material, but rather a function of the properties governing the thickness of the liquid film.

The inter-particle adhesive tensile stress within bulk materials was measured in order to gain an understanding of the ratio of internal to external forces. Based on the measured material characteristics, a method to assess the potential of bulk materials to cause handling problems has been developed. An adhesive threshold value has been introduced which has to be exceeded by a material to be characterized as wet and sticky. Additionally, the inter-particle adhesion of a sample has to be larger than the wall adhesion for a material to be characterized as wet and sticky. The threshold is to be further assessed with onsite data.

\section{REFERENCES}

1 Burbaum, U.: Adhäsion bindiger Böden an Werkstoffoberflächen von

Tunnelbohrmaschinen. TU Darmstadt, Fachbereich Material- und Geowissenschaften, FG Ingenieurgeologie Diss. 2009

2 Habenicht, G.: Kleben (5th ed.). Berlin, Heidelberg 2006

3 ASTM Standard D6128-06. Standard Test Method for Shear Testing of Bulk Solids Using the Jenike Shear Cell ASTM International, West Conshohoc 